\title{
BMJ Open The impact of heatwaves on mortality in Australia: a multicity study
}

\author{
Shilu Tong, ${ }^{1}$ Xiao Yu Wang, ${ }^{1}$ Weiwei Yu, ${ }^{1}$ Dong Chen, ${ }^{2}$ Xiaoming Wang ${ }^{2}$
}

To cite: Tong S, Wang XY, Yu W, et al. The impact of heatwaves on mortality in Australia: a multicity study. BMJ Open 2014;4:e003579. doi:10.1136/bmjopen-2013003579

- Prepublication history and additional material for this paper is available online. To view these files please visit the journal online (http://dx.doi.org/10.1136/ bmjopen-2013-003579).

Received 9 July 2013

Revised 3 November 2013

Accepted 18 November 2013

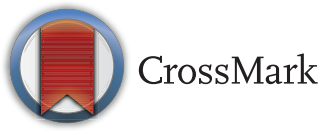

${ }^{1}$ School of Public Health \& Institute of Health and Biomedical Innovation, Queensland University of Technology, Brisbane, Queensland, Australia ${ }^{2}$ CSIRO Climate Adaptation Flagship and CSIRO Ecosystem Sciences, Melbourne, Victoria, Australia

Correspondence to Dr Shilu Tong:

s.tong@qut.edu.au

\section{ABSTRACT}

Objectives: To assess the heterogeneity of heatwaverelated impacts on mortality across different cities.

Design: A multicity time series study.

Setting: 3 largest Australian cities: Brisbane,

Melbourne and Sydney.

Participants: All residents living in these cities.

Main outcome measures: Non-external causes mortality data by gender and two age groups (ie, $0-75$ and 75+) for these cities during the period 1988-2009 were obtained from relevant government agencies.

Results: Total mortality increased mostly within the same day (lag 0 ) or a lag of 1 day (lag 1) during almost all heatwaves in three cities. Using the heatwave definition (HWD) as the 95th centile of mean temperature for two or more consecutive days in the summer season, the relative risk for total mortality at lag 1 in Brisbane, Melbourne and Sydney was 1.13 ( $95 \% \mathrm{Cl} 1.08$ to 1.19$), 1.10$ (95\% Cl 1.06 to 1.14 ) and $1.06(95 \% \mathrm{Cl} 1.01$ to 1.10$)$, respectively. Using the more stringent HWD-the 99th centile of mean temperature for two or more consecutive days, the relative risk of total mortality at the lags of $0-2$ days in Brisbane and Melbourne was $1.40(95 \% \mathrm{Cl} 1.29$ to $1.51)$ and $1.47(95 \% \mathrm{Cl} 1.36$ to 1.59$)$, respectively. Elderly, particularly females, were more vulnerable to the impact of heatwaves.

Conclusions: A consistent and significant increase in mortality was observed during heatwaves in the three largest Australian cities, but the impacts of heatwave appeared to vary with age, gender, the HWD and geographical area.

\section{INTRODUCTION}

It is well known that exposure to extreme temperatures has a significant impact on human health. For example, the 2003 heatwave caused over 70000 excess deaths in Europe. ${ }^{1}{ }^{2}$ A number of epidemiological studies have shown that the relationships between temperatures and mortality are often non-linear, with a J, U or $\mathrm{V}$ shape. $^{3-9}$ However, the key reasons why there are different non-linear curves in different population remain unknown. In addition, exposure to extreme temperatures usually does not reach the highest mortality at the same day, and

\section{Strengths and limitations of this study}

- This is the first multicity study on the mortality impacts of heatwaves in the Southern Hemisphere.

- The similarities and differences in the heatwave -mortality relationship across the three largest Australian cities were quantified.

- Potential confounding effects of air pollution were not controlled, as these data were not complete for the whole study period in all three cities (ie, Brisbane, Melbourne and Sydney).

often show lagged effects. ${ }^{10}{ }^{11}$ Some of this difference may be explained by inconsistent definitions, methodology as well as possibly population differences. Different heatwave definitions (HWDs) have been used in previous studies since there is currently no standard definition for heatwave. ${ }^{7} 1012$

Some studies have estimated the mortality effects of heatwaves across many countries, cities or communities, and determined how mortality increased during heatwaves. ${ }^{1-6} 81013$ Different research methods for estimating mortality associated with heatwaves have been used in previous studies. For example, a descriptive approach has been applied to compare the number of deaths between heatwave and non-heatwave days, ${ }^{14}$ a time-series analysis has been widely used to estimate mortality risks in association with hot or cold temperature $^{1011}$ and a case-crossover analysis is also another increasingly popular method used in this field. ${ }^{7} 1516$ However, recent evidence suggests that time-series analysis is still an effective and possibly the most applicable method for investigating the health impact of time-varying environmental exposures. ${ }^{17-19}$

Most of the Australian capital cities are located along the coast. There is a wide variation in climatic conditions across Australia. Most previous Australian studies have analysed the relationship between temperature and mortality for only one city and no research, to date, has been conducted to examine the health impact of heatwaves across different cities. ${ }^{16}{ }^{19-24}$ To better understand how 
temperature affects mortality in different locations, this study assessed the temperature-mortality relationship in the three largest Australian cities: Brisbane, Melbourne and Sydney, and attempted to quantify the impact of heatwaves on mortality in these areas.

\section{METHODS}

Brisbane, Melbourne and Sydney are the capital cities of Queensland, Victoria and New South Wales, respectively, in Australia. These three metropolitan cities are all located on the south-east coast of the continent (figure 1). There are about 2.2, 4.2 and 4.6 million residents in Brisbane, Melbourne and Sydney, respectively, in June 2011. ${ }^{25}$ Together, they represent approximately half of the Australia population of 22.3 million. ${ }^{25}$

\section{Data collection}

We obtained mortality data between 1988 and 2009 for Brisbane, Melbourne and Sydney from the Australian Bureau of Statistics (ABS). Owing to privacy protection reason, the data obtained from the ABS were limited for the Statistical Division of usual residence by gender and two age groups (ie, 0-75 and 75+) for the three metropolitan areas. In order to calculate the mortality rate, the corresponding populations by gender and the two age groups from 1988 to 2009 in the three cities were also extracted from the ABS database. Online supplementary table S1 presents the average of population size and percentage of $75+$ years old by gender between 1988 and 2009 .

Daily climate data on maximum and minimum temperatures and relative humidity for the same period (1988-2009) were acquired from the Australian Bureau of Meteorology. We selected all available meteorological stations located within $\leq 30 \mathrm{~km}$ of each city's Central Business District (CBD) (7 stations in Brisbane, 7 stations in Melbourne and 11 stations in Sydney). We calculated the daily averages of climatic variables using all records from meteorological stations in each city. This approach is used in previous research. ${ }^{18}$ There were approximately $1.4-5.1^{\circ} \mathrm{C}$ differences for maximum or minimum temperature between meteorological stations of each city. When there was a missing value $(\leq 1.3 \%)$ for a particular meteorological station, observations recorded from the remaining weather stations were used to compute the daily average values.

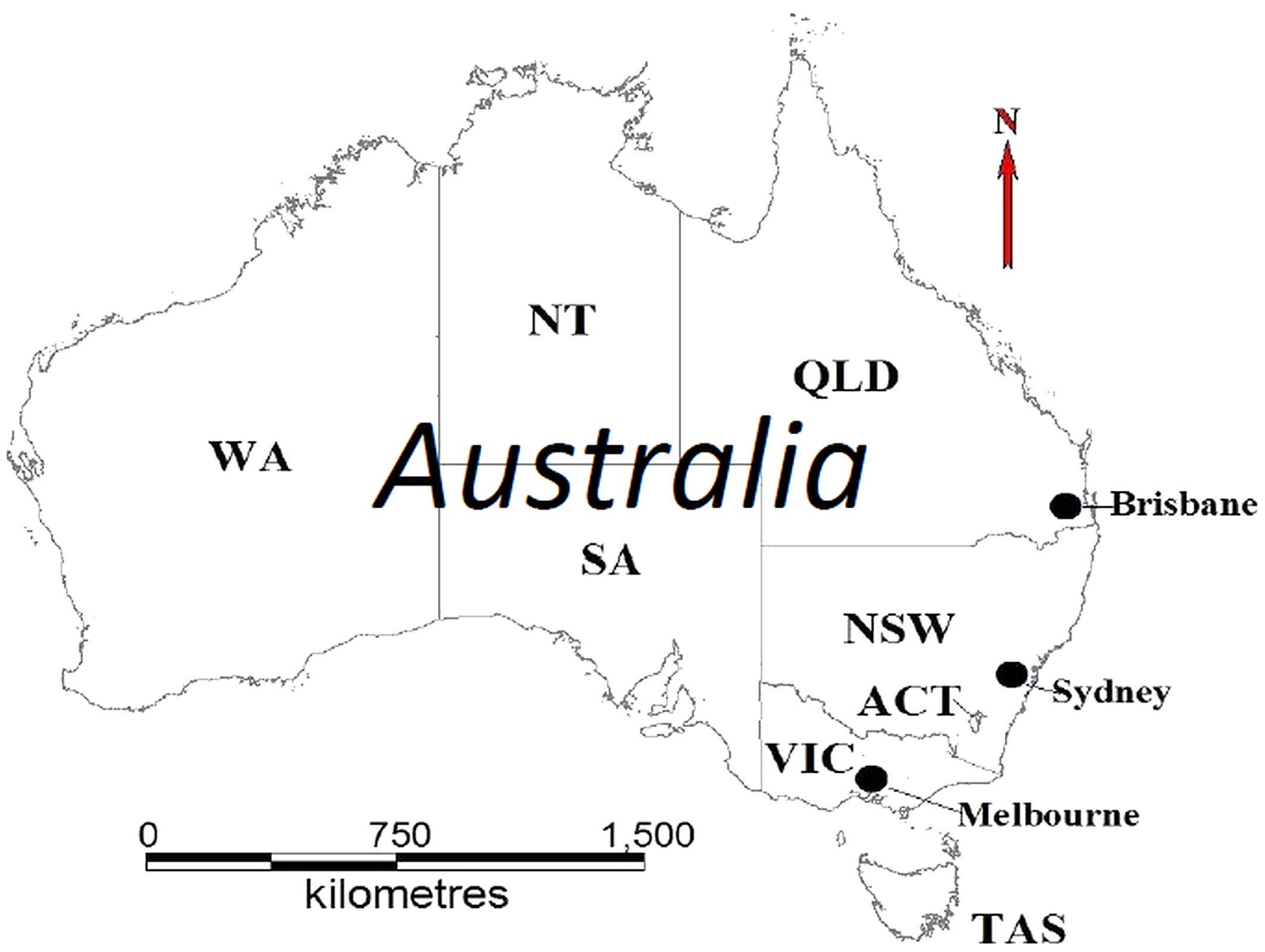

Figure 1 Locations of Brisbane, Melbourne and Sydney in Australia. 
Table 1 Summary of the daily climatic variables and mortality in summer season* (1988-2009)

\begin{tabular}{|c|c|c|c|c|c|c|c|c|c|c|c|c|}
\hline \multirow[b]{2}{*}{ Variable } & \multicolumn{4}{|c|}{ Brisbane } & \multicolumn{4}{|c|}{ Melbourne } & \multicolumn{4}{|c|}{ Sydney } \\
\hline & Mean & SD & Minimum & $\overline{\text { Maximum }}$ & Mean & SD & Minimum & Maximum & Mean & SD & Minimum & Maximum \\
\hline \multicolumn{13}{|l|}{ Male } \\
\hline (AII) & 12 & 3.9 & 2 & 38 & 27 & 5.7 & 11 & 52 & 32 & 7.1 & 6 & 74 \\
\hline$(0-74)$ & 6 & 2.8 & 0 & 17 & 13 & 4.6 & 1 & 33 & 16 & 5.9 & 2 & 47 \\
\hline$(75+)$ & 6 & 2.8 & 0 & 25 & 14 & 4.4 & 2 & 34 & 15 & 4.5 & 3 & 32 \\
\hline \multicolumn{13}{|l|}{ Female } \\
\hline (All) & 12 & 4.1 & 1 & 40 & 26 & 5.7 & 10 & 79 & 30 & 6.7 & 9 & 70 \\
\hline$(0-74)$ & 4 & 2.1 & 0 & 13 & 8 & 3.3 & 1 & 21 & 10 & 3.8 & 1 & 32 \\
\hline$(75+)$ & 8 & 3.3 & 0 & 30 & 18 & 5.0 & 3 & 64 & 21 & 5.4 & 5 & 42 \\
\hline Total & 24 & 6.2 & 4 & 68 & 54 & 8.6 & 23 & 127 & 62 & 11.1 & 20 & 136 \\
\hline $\operatorname{Max} T \dagger\left({ }^{\circ} \mathrm{C}\right)$ & 29.3 & 2.3 & 20.1 & 40.1 & 25.6 & 5.8 & 13.9 & 46.7 & 27.1 & 4.0 & 16.6 & 44.0 \\
\hline MeanT $\neq\left({ }^{\circ} \mathrm{C}\right)$ & 24.8 & 1.9 & 18.3 & 33.6 & 19.7 & 3.9 & 10.9 & 35.5 & 22.5 & 2.7 & 15.1 & 33.2 \\
\hline $\operatorname{MinT} \S\left({ }^{\circ} \mathrm{C}\right)$ & 20.3 & 2.2 & 11.9 & 27.1 & 13.8 & 3.3 & 5.8 & 27.6 & 18.0 & 2.3 & 9.8 & 25.8 \\
\hline $\mathrm{RH} \emptyset(\%)$ & 70.2 & 8.7 & 30.2 & 96.8 & 65.0 & 11.6 & 19.7 & 95.6 & 70.0 & 11.0 & 28.1 & 98.1 \\
\hline
\end{tabular}

\section{Data analysis}

Previous studies have found that mean temperature was a slightly better predictor of mortality than maximum or minimum temperature in Brisbane. ${ }^{26}$ Thus in this study, we used mean temperature as an indicator of exposure. Daily mean temperatures (ie, averaged values of maximum and minimum temperatures) were used to investigate the effects of heatwaves on mortality in these three cities. A heatwave was defined as the mean temperature above a heat threshold (ie, 90th, 95th and 99th centiles of mean temperature) for 2 or more consecutive days in the summer season (1 December to the end of February of next year). A binary heatwave variable ( 1 or 0 ) was used for each day (eg, 1 for the heatwave days meant that temperatures were equal to or higher than the 99th centile for two or more consecutive days; 0 for nonheatwave days). A Poisson generalised additive model (GAM) was used to examine single (eg, lag 0,1 and 2) and cumulative lag effects (lag 0-2) of heatwaves on mortality for each city, after adjustment for humidity and population as confounding factors. The 'mgcv' package in $\mathrm{R}$ software (V.2.14.1) was used to fit the time series GAM.

\section{RESULTS}

Table 1 describes the statistical summary of climatic variables and health outcomes for each city in summer seasons. The highest mean temperature reached $33.6^{\circ} \mathrm{C}$ in Brisbane (22 February 2004), $35.5^{\circ} \mathrm{C}$ in Melbourne (29 January 2009) and $33.2^{\circ} \mathrm{C}$ in Sydney (1 January 2006). However, Brisbane had the higher average mean temperature $\left(24.8^{\circ} \mathrm{C}\right)$ than Melbourne $\left(19.7^{\circ} \mathrm{C}\right)$ and Sydney $\left(22.5^{\circ} \mathrm{C}\right)$. Similar patterns were observed for the average maximum and minimum temperatures.

Table 2 indicates the heatwave days and threshold $\left({ }^{\circ} \mathrm{C}\right)$ using different percentiles of mean temperatures.
Online supplementary table S2 also provided the heatwave days separated by early summer and later summer. Overall, Brisbane had more heatwave days than Melbourne and Sydney across all HWDs during the study period. This is not unexpected and may simply be because Brisbane is further north with subtropical climatic conditions. Online supplementary figure S1 shows the distribution of daily mortality data by mean temperature for each city. The temperature-mortality relations appeared to be a $\mathrm{U}$ shape across three cities.

Figure 2 shows the distributed lag structure (lag 0 to lag 7) of the heatwave effects on mortality using $95 \%$ percentiles of mean temperature as the HWD in three cities after adjustment for relative humidity and population size. Heatwave-related mortality mostly occurred within the same day (lag 0) or a lag of 1 day (lag 1) in the three cities. Heatwaves also appeared to have greater impact on females and total mortality. For example, the relative risk (RR) for total mortality in Brisbane, Melbourne and Sydney was 1.13 (95\% CI 1.08 to 1.19), 1.10 (95\% CI 1.06 to 1.14 ) and 1.06 (95\% CI 1.01 to 1.10$)$, respectively, at lag 1. A similar pattern was found if mean temperatures

Table 2 HWD used in three cities (1988-2009)

\begin{tabular}{lrlrlrl}
\hline & \multicolumn{6}{c}{ Heatwave days and threshold } \\
\cline { 2 - 7 } HWD* $^{*}$ Brisbane & \multicolumn{3}{c}{ Melbourne } & \multicolumn{2}{c}{ Sydney } \\
\hline $99 \%$ & 11 & $29.7^{\circ} \mathrm{C}$ & 4 & $30.1^{\circ} \mathrm{C}$ & 0 & $29.6^{\circ} \mathrm{C}$ \\
$95 \%$ & 70 & $28.0^{\circ} \mathrm{C}$ & 56 & $27.2^{\circ} \mathrm{C}$ & 37 & $27.3^{\circ} \mathrm{C}$ \\
$90 \%$ & 153 & $27.2^{\circ} \mathrm{C}$ & 128 & $25.3^{\circ} \mathrm{C}$ & 118 & $26.1^{\circ} \mathrm{C}$ \\
\hline
\end{tabular}

${ }^{*} \mathrm{HWDs}$ were defined as the mean temperature above the centiles (ie, 90th, 95th or 99th centile) for 2 or more consecutive days in the summer season (1 December to the end of February of next year).

HWD, heatwave definition. 


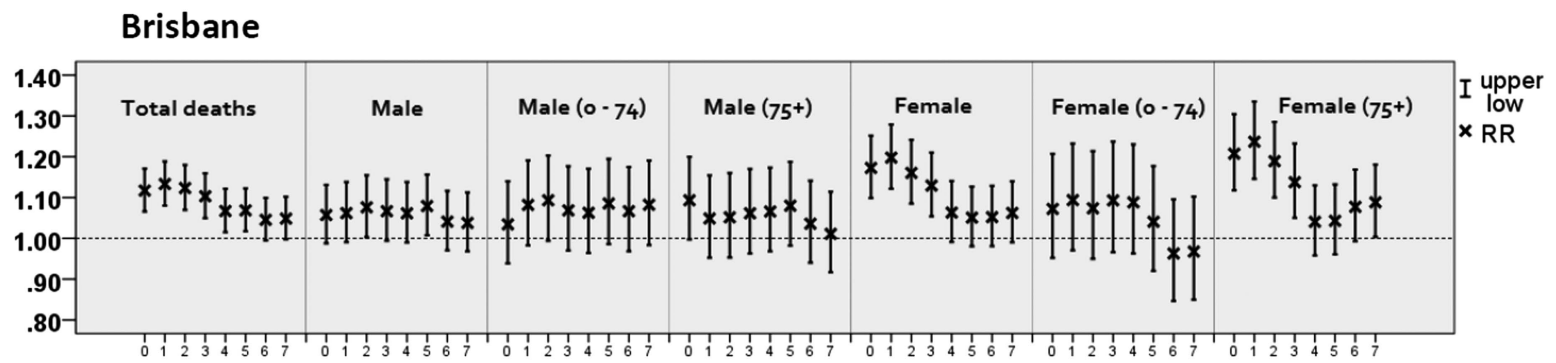

Melbourne

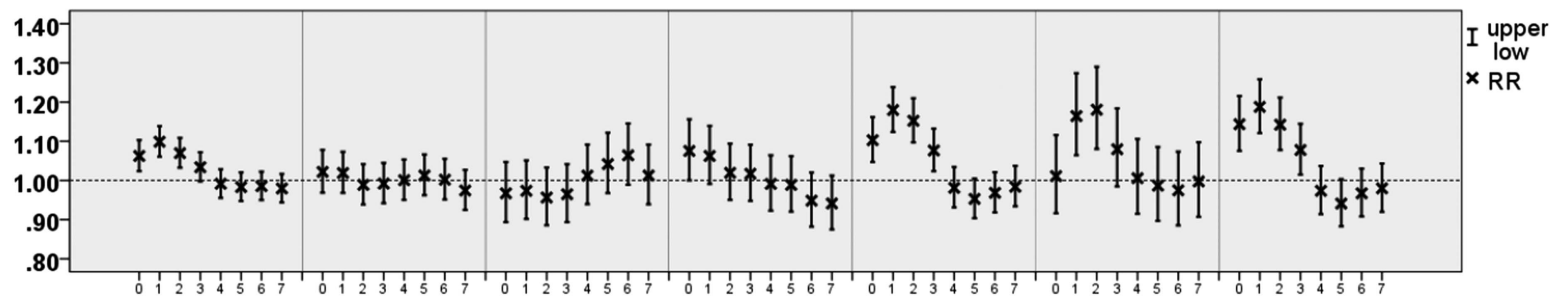

Sydney

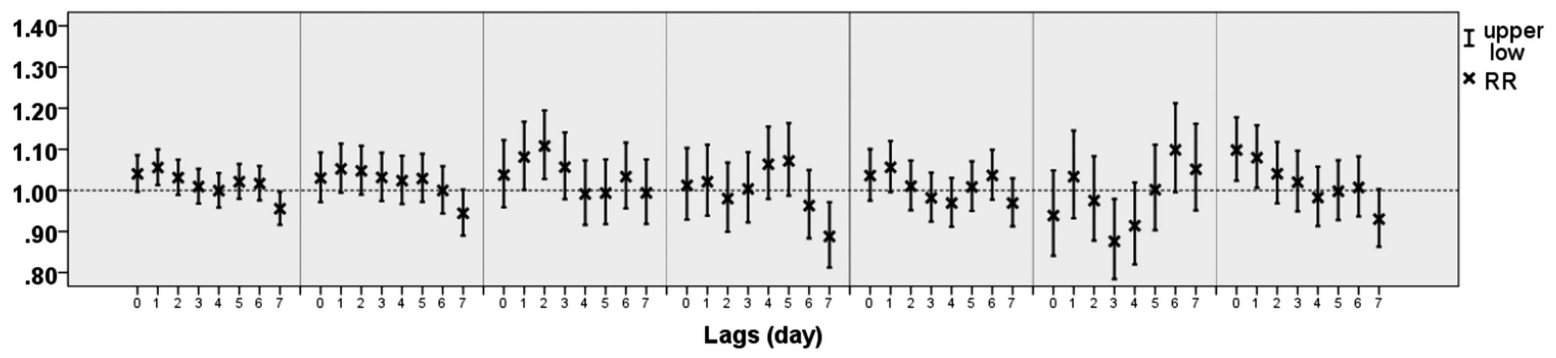

Figure 2 Distributed lag structure of the heatwave effects on mortality by sex, age and city. Cross symbols denote the mean relative risk (RR) and the vertical lines represent the $95 \%$ Cls.

were replaced with maximum temperatures in the HWD in these cities (results not shown).

Table 3 reveals the RRs of daily mortality during heatwaves using different percentiles of mean temperature as thresholds for cumulative lag effects (lag 0-2 days) in the three cities after adjustment for relative humidity and population size. Heatwaves appeared to have greater impact on females and total mortality, especially in females aged 75 and over, regardless of which definition of heatwave was used. However, heatwaves appeared to affect local residents more in Brisbane and Melbourne than in Sydney, which may be because Sydney had fewer prolonged hot days than other cities. For example, no heatwave was recorded in Sydney during the study periods if the definition of 99th centile of mean temperature for two or more consecutive days was used (table 2).

\section{DISCUSSION}

This is the first study to use locally defined definitions to investigate the relationship between heatwaves and mortality in different Australian cities. The principal finding of this study is that there was a consistent and statistically significant relationship between hot temperatures and mortality in the three largest Australian cities: Brisbane, Melbourne and Sydney.

Several mortality studies have reported the impact of heatwaves on mortality. ${ }^{10} 2728$ The results of this study support the findings from previous research. In general, heatwaves are associated with significantly increased mortality across all three cities. However, heatwaves appeared to affect mortality more in Brisbane and Melbourne than in Sydney. This may be due to the fact that Sydney had fewer prolonged hot days than Brisbane and Melbourne (table 2). Additionally, adaptation (eg, more usage of air conditioning in Sydney) and people's behaviour may also play a role. Online supplementary table S2 shows that the total number of deaths during heatwave periods in the late summer was greater than that in the early summer. For example, if the heatwave was defined as the 95th centile for two or more consecutive days, 4566 people died during heatwave periods across three cities in the late summer, compared with 2720 died in the early summer. Our results show that the elderly $(\geq 75)$, especially females, were more vulnerable to heatwave effects than others in these cities. This finding supports previous studies that the female elderly were particularly vulnerable to heat effects. ${ }^{29}{ }^{30}$ There may be an adverse effect of menopause on thermoregulation, in addition to its 
Table 3 RR of mortality by different HWDs for cumulative lag effects (lag 0-2) in three cities, 1988-2009

\begin{tabular}{|c|c|c|c|}
\hline \multirow[b]{2}{*}{ HWD† } & \multicolumn{3}{|l|}{$\mathrm{RR}^{*}(95 \% \mathrm{Cl})$} \\
\hline & Brisbane & Melbourne & Sydney \\
\hline \multicolumn{4}{|l|}{ Male } \\
\hline $99 \%$ & 1.32 (1.17 to 1.48$)$ & 1.37 (1.22 to 1.53$)$ & NAł \\
\hline $95 \%$ & 1.04 (0.99 to 1.10$)$ & $1.00(0.96$ to 1.04$)$ & $1.03(0.99$ to 1.08$)$ \\
\hline $90 \%$ & 1.01 (0.97 to 1.05$)$ & 1.02 (0.99 to 1.05$)$ & 1.04 (1.01 to 1.06$)$ \\
\hline \multicolumn{4}{|l|}{$(0-74)$} \\
\hline $99 \%$ & $1.29(1.10$ to 1.53$)$ & $1.37(1.15$ to 1.63$)$ & NA \\
\hline $95 \%$ & $1.04(0.96$ to 1.12$)$ & 0.96 (0.91 to 1.02$)$ & $1.07(1.01$ to 1.13$)$ \\
\hline $90 \%$ & 0.99 (0.93 to 1.04$)$ & $1.00(0.96$ to 1.04$)$ & 1.04 (1.00 to 1.08$)$ \\
\hline \multicolumn{4}{|l|}{$(75+)$} \\
\hline $99 \%$ & 1.33 (1.13 to 1.56$)$ & 1.38 (1.19 to 1.61$)$ & NA \\
\hline $95 \%$ & $1.05(0.97$ to 1.13$)$ & 1.04 (0.98 to 1.09$)$ & $0.99(0.92$ to 1.05$)$ \\
\hline $90 \%$ & 1.03 (0.97 to 1.08$)$ & 1.03 (0.99 to 1.07$)$ & 1.03 (1.00 to 1.07$)$ \\
\hline \multirow{2}{*}{\multicolumn{4}{|c|}{$\begin{array}{l}\text { Female } \\
\text { (all) }\end{array}$}} \\
\hline & & & \\
\hline $99 \%$ & $1.45(1.30$ to 1.61$)$ & 1.57 (1.41 to 1.74$)$ & NA \\
\hline $95 \%$ & 1.13 (1.07 to 1.19$)$ & 1.11 (1.07 to 1.15$)$ & $1.03(0.98$ to 1.07$)$ \\
\hline $90 \%$ & 1.06 (1.02 to 1.10$)$ & 1.05 (1.02 to 1.07$)$ & 1.05 (1.03 to 1.08$)$ \\
\hline \multicolumn{4}{|l|}{$(0-74)$} \\
\hline $99 \%$ & $1.08(0.86$ to 1.34$)$ & 1.46 (1.18 to 1.81$)$ & NA \\
\hline $95 \%$ & $1.06(0.96$ to 1.17$)$ & $1.10(1.03$ to 1.18$)$ & $0.97(0.90$ to 1.05$)$ \\
\hline $90 \%$ & $1.04(0.96$ to 1.11$)$ & 1.04 (0.99 to 1.09$)$ & 1.04 (0.99 to 1.09$)$ \\
\hline \multicolumn{4}{|l|}{$(75+)$} \\
\hline $99 \%$ & 1.61 (1.42 to 1.82$)$ & 1.63 (1.44 to 1.85$)$ & NA \\
\hline $95 \%$ & 1.15 (1.08 to 1.22$)$ & 1.12 (1.07 to 1.17$)$ & 1.06 (1.01 to 1.12$)$ \\
\hline $90 \%$ & 1.07 (1.02 to 1.12$)$ & 1.05 (1.01 to 1.08$)$ & 1.06 (1.03 to 1.09$)$ \\
\hline \multicolumn{4}{|l|}{ Total } \\
\hline $99 \%$ & 1.40 (1.29 to 1.51$)$ & 1.47 (1.36 to 1.59$)$ & NA \\
\hline $95 \%$ & 1.09 (1.05 to 1.13$)$ & 1.06 (1.03 to 1.09$)$ & $1.03(1.00$ to 1.07$)$ \\
\hline $90 \%$ & 1.04 (1.01 to 1.07$)$ & $1.03(1.01$ to 1.05$)$ & 1.04 (1.03 to 1.06$)$ \\
\hline \multicolumn{4}{|c|}{$\begin{array}{l}\text { Adjusted for relative humidity, days of week and population size. } \\
\text { *Relative risk (RR). } \\
\text { †HWDs were defined as different centiles (ie, } 90 \text { th, } 95 \text { th or } 99 \text { th centile) of mean temperature for two or more consecutive days in the } \\
\text { summer season. } \\
\text { †Not applicable. } \\
\text { HWD, heatwave definition. } \\
\text { Bold typeface indicates statistical significance at } p<0.05 \text {. }\end{array}$} \\
\hline
\end{tabular}

effects on cardiovascular fitness. ${ }^{30}$ Some important social factors (eg, living alone or low income) may also explain differences in mortality patterns between males and females during heatwaves. 3132

We investigated single and cumulative lag effects since some studies have identified the increased risk for temperature-related mortality from exposure occurring on the same day or a few days previously. ${ }^{10} \quad 11 \quad 15 \quad 16$ In this study, we reported that the impact of strongest heatwaves was usually observed on the same day or the next day across all three cities (figure 2). Thus, we concur with the notion that heatwaves usually have acute and dramatic impacts on mortality.

The findings of this study are comparable with some previous multicity studies (eg, USA or Europe). ${ }^{813}$ There are three similarities across these studies: (1) a similar magnitude of heatwave effects was observed; (2) the impacts of heatwave occurred rapidly and there were no apparent long-term lag effects and (3) elderly are more vulnerable to the impacts of heatwave than others. However, there are also some differences across these studies. For example, a previous study ${ }^{8}$ found that mortality increased to high levels during heatwaves in early summer than those in late summer, but our results show that higher mortality was resulted from heatwaves in mid or late summer for all three cities (see online supplementary table S2), which may be because more intense heatwaves usually occur in mid or late summer in Australia.

There were some limitations in this study. We did not control for the potential confounding effects of air pollution (eg, ozone), as these data were not complete for the whole study period in all three cities. However, previous studies have reported the health impacts of a heatwave as occurring independent of air pollution. ${ }^{10} 33$ A relatively small number of heatwave days may explain why the differences in heat effects between the three cities as well as the subpopulations were not statistically significant as their 95\% CIs were overlapped each other. Additionally, the 
mortality data for three cities only included two age groups (0-74 and $75+)$ by gender. Thus, we were unable to divide the data into smaller age groups.

\section{CONCLUSIONS}

A consistent and significant increase in mortality was observed during heatwaves in the three Australian metropolitan cities, but the impacts of heatwave appeared to vary with age, gender, the HWD and geographical area. Extreme hot temperatures appeared to directly result in an increased risk of mortality in these cities. The most vulnerable groups were the elderly, especially females aged 75 and over. By better understanding heatwave effects on mortality, local government and communities can develop appropriate public health strategies and increase their adaptive capacity to prevent and mitigate the impact of heatwave.

Acknowledgements The authors would like to thank the Queensland Health, Australian Bureau of Statistics and Australia Bureau of Meteorology for providing the relevant data.

Contributors ST contributed to the design and coordinated the study. XYW conducted the data analyses. ST and XYW wrote the first draft of the article. All authors critically reviewed and approved the final version of the manuscript.

Funding This study was partly funded by the Australian Research Council (LP882699), Horticulture Australia Limited using the Nursery Industry Levy (Project \# NY 11013) and Commonwealth Scientific and Industrial Research Organisation (CSIRO) Climate Adaptation Flagship, the Queensland Department of Environment and Resources Management, Department of Community Safety, Queensland Health and the Environmental Protection Agency.

Competing interests ST was supported by the National Health and Medical Research Council (NHMRC) research fellowship.

Ethics approval An ethical approval was granted by the Human Research Ethics Committee, Queensland University of Technology, Australia.

Provenance and peer review Not commissioned; externally peer reviewed.

Data sharing statement No additional data are available.

Open Access This is an Open Access article distributed in accordance with the Creative Commons Attribution Non Commercial (CC BY-NC 3.0) license, which permits others to distribute, remix, adapt, build upon this work noncommercially, and license their derivative works on different terms, provided the original work is properly cited and the use is non-commercial. See: http:// creativecommons.org/licenses/by-nc/3.0/

\section{REFERENCES}

1. Le Tertre A, Lefranc A, Eilstein D, et al. Impact of the 2003 heatwave on all-cause mortality in 9 French cities. Epidemiology 2006;17:75-9.

2. Robine JM, Cheung SL, Le Roy S, et al. Death toll exceeded 70,000 in Europe during the summer of 2003. C R Biol 2008;331:171-8.

3. McMichael AJ, Wilkinson P, Kovats RS, et al. International study of temperature, heat and urban mortality: the 'ISOTHURM' project. Int $J$ Epidemiol 2008;37:1121-31.

4. Knowlton K, Rotkin-Ellman M, King G, et al. The 2006 California heat wave: impacts on hospitalizations and emergency department visits. Environ Health Perspect 2009;117:61-7.

5. O'Neill MS, Zanobetti A, Schwartz J. Modifiers of the temperature and mortality association in seven US cities. Am J Epidemiol 2003;157:1074-82.

6. Stafoggia M, Forastiere F, Agostini D, et al. Vulnerability to heat-related mortality: a multicity, population-based, case-crossover analysis. Epidemiology 2006;17:315-23.
7. Tong S, Wang XY, Barnett AG. Assessment of heat-related health impacts in Brisbane, Australia: comparison of different heatwave definitions. PLOS ONE 2010;5:e12155.

8. Anderson GB, Bell ML. Heat waves in the United States: mortality risk during heat waves and effect modification by heat wave characteristics in 43 U.S. communities. Environ Health Perspect 2011;119:210-18.

9. Hajat $S$, Kosatky T. Heat-related mortality: a review and exploration of heterogeneity. J Epidemiol Community Health 2010;64:753-60.

10. Anderson BG, Bell ML. Weather-related mortality: how heat, cold, and heat waves affect mortality in the United States. Epidemiology 2009;20:205-13.

11. Yu W, Mengersen K, Hu W, et al. Assessing the relationship between global warming and mortality: lag effects of temperature fluctuations by age and mortality categories. Environ Pollut 2011;159:1789-93.

12. Gasparrini A, Armstrong B. The impact of heat waves on mortality. Epidemiology 2011;22:68-73.

13. Baccini M, Kosatsky T, Analitis A, et al. Impact of heat on mortality in 15 European cities: attributable deaths under different weather scenarios. J Epidemiol Community Health 2011;65:64-70.

14. Grize L, Huss A, Thommen O, et al. Heat wave 2003 and mortality in Switzerland. Swiss Med Wkly 2005;135:200-5.

15. Basagana X, Sartini C, Barrera-Gomez J, et al. Heat waves and cause-specific mortality at all ages. Epidemiology 2011;22:765-72.

16. Wang XY, Barnett AG, Yu W, et al. The impact of heatwaves on mortality and emergency hospital admissions from non-external causes in Brisbane, Australia. Occup Environ Med 2012; 69:163-9.

17. Guo Y, Barnett AG, Zhang $Y$, et al. The short-term effect of air pollution on cardiovascular mortality in Tianjin, China: comparison of time series and case-crossover analyses. Sci Total Environ 2010;409:300-6.

18. Tong S, Wang XY, Guo Y. Assessing the short-term effects of heatwaves on mortality and morbidity in Brisbane, Australia: comparison of case-crossover and time series analyses. PLOS ONE 2012;7:e37500.

19. Guo Y, Barnett AG, Tong S. Spatiotemporal model or time series model for assessing city-wide temperature effects on mortality? Environ Res 2013;120:55-62.

20. Williams S, Nitschke $\mathrm{M}$, Weinstein $\mathrm{P}$, et al. The impact of summer temperatures and heatwaves on mortality and morbidity in Perth, Australia 1994-2008. Environ Int 2012;40:33-8.

21. Schaffer A, Muscatello D, Broome R, et al. Emergency department visits, ambulance calls, and mortality associated with an exceptional heat wave in Sydney, Australia, 2011: a time-series analysis. Environ Health 2012;11:3.

22. Vaneckova P, Beggs PJ, Jacobson CR. Spatial analysis of heat-related mortality among the elderly between 1993 and 2004 in Sydney, Australia. Soc Sci Med 2010;70:293-304.

23. Huang $C$, Barnett AG, Wang $X$, et al. Effects of extreme temperatures on years of life lost for cardiovascular deaths: a time series study in Brisbane, Australia. Circ Cardiovasc Qual Outcomes 2012;5:609-14.

24. Guest CS, Willson K, Woodward AJ, et al. Climate and mortality in Australia: retrospective study, 1979-1990, and predicted impacts in five major cities in 2030. Climate Res 1999;13:1-15.

25. ABS. Australian Bureau of Statistics: Regional Population Growth, Australia, 2011. http://www.abs.gov.au/ausstats/abs@.nsf $/ \mathrm{mf} / 3218.0$

26. Vaneckova P, Neville G, Tippett $\mathrm{V}$, et al. Do biometeorological indices improve modeling outcomes of heat-related mortality? J Appl Meteor Climatol 2011;50:1165-76.

27. Schifano $\mathrm{P}$, Leone $\mathrm{M}$, De Sario $\mathrm{M}$, et al. Changes in the effects of heat on mortality among the elderly from 1998-2010: results from a multicenter time series study in Italy. Environ Health 2012;11:58.

28. Barnett AG, Tong S, Clements AC. What measure of temperature is the best predictor of mortality? Environ Res 2010;110:604-11.

29. Yu W, Vaneckova P, Mengersen K, et al. Is the association between temperature and mortality modified by age, gender and socio-economic status? Sci Total Environ 2010;408:3513-18.

30. Hajat S, Kovats RS, Lachowycz K. Heat-related and cold-related deaths in England and Wales: who is at risk? Occup Environ Med 2007;64:93-100.

31. Kim Y, Joh S. A vulnerability study of the low-income elderly in the context of high temperature and mortality in Seoul, Korea. Sci Total Environ 2006;371:82-8.

32. Stafoggia M, Forastiere F, Agostini D, et al. Factors affecting in-hospital heat-related mortality: a multi-city case-crossover analysis. J Epidemiol Community Health 2008;62:209-15.

33. Tong S, Ren C, Becker N. Excess deaths during the 2004 heatwave in Brisbane, Australia. Int J Biometeorol 2010;54:393-400. 